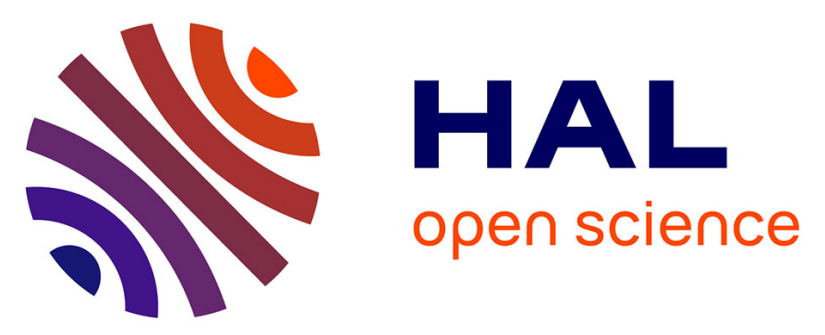

\title{
Increasing incidence of breast cancer: distinguishing between the effects of birth cohort and a national breast screening programme
}

Sylvia B. F. Brown, David S. Morrison, Timothy G. Cooke

\section{To cite this version:}

Sylvia B. F. Brown, David S. Morrison, Timothy G. Cooke. Increasing incidence of breast cancer: distinguishing between the effects of birth cohort and a national breast screening programme. Breast Cancer Research and Treatment, 2008, 116 (3), pp.603-607. 10.1007/s10549-008-0205-0 . hal00478270

\author{
HAL Id: hal-00478270 \\ https://hal.science/hal-00478270
}

Submitted on 30 Apr 2010

HAL is a multi-disciplinary open access archive for the deposit and dissemination of scientific research documents, whether they are published or not. The documents may come from teaching and research institutions in France or abroad, or from public or private research centers.
L'archive ouverte pluridisciplinaire HAL, est destinée au dépôt et à la diffusion de documents scientifiques de niveau recherche, publiés ou non, émanant des établissements d'enseignement et de recherche français ou étrangers, des laboratoires publics ou privés. 


\title{
Increasing incidence of breast cancer: distinguishing between the effects of birth cohort and a national breast screening programme
}

\author{
Sylvia B. F. Brown · David S. Morrison • \\ Timothy G. Cooke
}

Received: 13 April 2008/Accepted: 19 September 2008/Published online: 15 October 2008

(C) Springer Science+Business Media, LLC. 2008

\begin{abstract}
The incidence of breast cancer in post-menopausal women has been affected by the introduction of national breast screening programmes. The study describes the incidence of breast cancer in Scottish women aged 5064 by year of birth before, during, and after the prevalent round of screening. Breast cancer registrations in Scotland for women aged 45-69 years from 1977 to 2003 were obtained. Birth cohort incidence rates were calculated and interpreted in the light of screening patterns at particular calendar time points. In the years before screening, there was a small rise in breast cancer incidence by birth cohort in women aged 50-54 which was not seen in other ages. During the prevalent screening round, incidence increased significantly with increasing birth cohort and thereafter continued rises in incidence by birth cohort occurred. The observed rise in breast cancer incidence among post-menopausal women is likely to be due to both screening effects and a true increase in incidence.
\end{abstract}

Keywords Breast - Cancer - Epidemiology - Incidence · Screening $\cdot$ Cohort

\footnotetext{
S. B. F. Brown $(\bowtie) \cdot$ T. G. Cooke

University Department of Surgery, Glasgow Royal Infirmary, Alexandra Parade, Glasgow G31 2ER, Scotland, UK

e-mail: sylvg82@hotmail.com

D. S. Morrison

West of Scotland Cancer Surveillance Unit, Division of Community Based Sciences, University of Glasgow, Glasgow, Scotland, UK
}

\section{Introduction}

The incidence of breast cancer in Scotland is rising in common with many other countries, with the increase being greatest among post-menopausal women [1-3]. The increase may be artefactual or real. The most likely explanation for an artefactual increase is the introduction of a national breast screening programme, which would be expected to detect earlier, asymptomatic breast cancers and thus result in a transient rise in incidence during its initial "prevalent" round $[4,5]$. In Scotland, the prevalent round of screening began in 1987 and was gradually extended throughout the country to all eligible women aged 5064 years by 1994 . An age extension to 70 years was introduced in certain areas of Scotland in 2003.

A true increase in incidence of breast cancer might be due to changing reproductive patterns $[2,6]$ as nulliparity and late age at first pregnancy are significant risk factors for the development of the disease [7-10]. Populationbased changes in other factors such as alcohol consumption may also be contributing [11]. Changing fertility patterns are postulated to have a distinct cohort effect on breast cancer incidence rates [2, 3, 9]. Women born in the same year or year range (birth cohort) can be expected to have similar incidence rates at any age as a result of similar population 'risk exposure' during their reproductive years. However, these birth cohort effects are altered by the introduction of a national breast screening programme as it selectively increases cancer detection in some birth cohorts in particular calendar years.

We have not identified published analyses of breast cancer trends that have attempted to disentangle these artefactual and real components of rising incidence rates. Our aim was to describe patterns of breast cancer incidence in Scotland over a period when the first round of a national 
breast cancer screening programme was introduced and completed and to distinguish between birth cohort effects (which might indicate true changes in incidence) and the effects of screening.

\section{Methods}

We obtained data on all new diagnoses of female breast cancer in Scotland between the calendar years 1977 and 2003 inclusive from the Scottish Cancer Registry, which operates within the Information Services Division of the NHS in Scotland. The Registry collects all incident cases of cancer nationwide via a compulsory notification system. Age and year specific breast cancer incidence rates per 100,000 were supplied to us for women aged 45-69 years. We calculated 5 calendar year mean incidence rates for ages 45-49, 50-54, 55-59, 60-64 and 65-69 for each birth year cohort from 1920 to 1949 . We identified the point-if there was one-at which each birth cohort became eligible for screening in the initial round between 1987 and 1994. Breast cancer incidence rates were then plotted against birth year for each age range in a Lexis diagram, with the period indicated at which eligibility for screening began. Ninety five percent confidence intervals for the differences in breast cancer incidence rates between years were calculated using the method described by Altman and others for differences in proportions for paired samples [12]. Data on the NHS Breast Screening Programme in Scotland itself were also requested from the Information Services Division in order to aid the interpretation of the findings.

\section{Results}

In Scottish women the age-adjusted (to European population) incidence rate of breast cancer has increased by
$46 \%$ from $80.7 / 10^{5}$ women in 1977 to $118.0 / 10^{5}$ in 2003 . In women aged 45-69 the crude incidence rate increased from $178.2 / 10^{5}$ women in 1977 to $293.9 / 10^{5}$ in 2003 , an increase of $65 \%$ (an increase of $115.7 / 10^{5}$, CI 73.2 158.2). Figure 1 shows breast cancer incidence rates in women aged 50-64 by birth year cohort, with incidence rates grouped by 5-year age-group. Each point represents the age-group mean incidence rate of women born in the same year. The data for each point are therefore necessarily drawn from 5 calendar years and can be interpreted as rolling averages. For example, women born in 1933 were aged 50-54 between 1983 and 1987. Some of the 50-54-year old age-group who were born in 1933 were thus eligible for screening when the round began in 1987 , albeit only those aged 54. In the 1934 birth cohort, only 53 and 54-year olds were eligible for screening. The 1937 birth cohort was thus the first in which all 50-54-year olds were eligible for screening in the prevalent round. Similarly, as women in the oldest ages of any age-group reach the end of the prevalent round in 1994 they will then go on to be screened during the established ("incident") round of screening. Thus the 1940 cohort is the last in which all 50-54-year olds might be part of the prevalent screening round.

Figure 1 shows that the incidence of breast cancer was higher with increasing age between 50 and 64 years. This was consistently found in all birth year cohorts. In 50-54year olds and 55-59-year olds there were small increases in incidence with birth cohort year before the screening programme began. In all age-groups there were significant rises in incidence throughout the duration of the prevalent round. The fall in incidence that was expected after the majority of Scottish women had been screened at least once [4] was not observed. Large rises in breast cancer incidence with increasing birth cohort continued after the screening programme had been fully established (although as described below, the confidence intervals were wide).
Fig. 1 Breast cancer incidence in women aged 50-64 years, by year of birth and age, 19772003. For each age-group, "1987" and "1994" mark the points when the oldest individuals began and ceased, respectively, to be eligible for the prevalent screening round

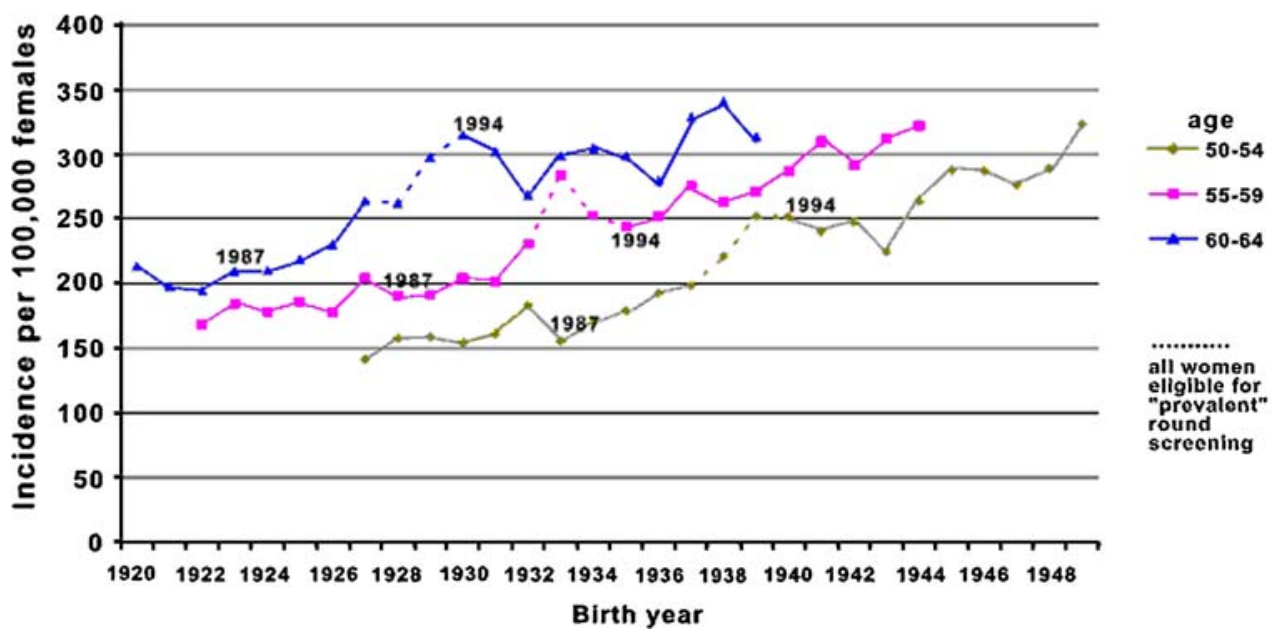


Rising incidence with increasing birth cohort occurred in parallel across all three age categories.

In 50-54-year olds, cohort incidence changed from 141.7 to $183.0 / 10^{5}$ in the years before screening (a rise of $41.3 / 10^{5}, 95 \%$ CI $6.1-76.5$ ); from 155.7 to $263.8 / 10^{5}$ (a rise of $\left.108.1 / 10^{5}, 95 \% \mathrm{CI} 68-148.2\right)$ in cohorts where some or all women were eligible for screening in the prevalent round; and from 287.5 to $323.5 / 10^{5}$ (a rise of $35.9 / 10^{5}$, 95\% CI -12.45 to 82.9$)$ in cohorts where women were entering an established screening programme. In 55-59-year olds, cohort incidence changed from 168.0 to $204.2 / 10^{5}$ in the years before screening (a rise of $36.2 / 10^{5}, 95 \% \mathrm{CI}-1.5$ to 73.9 ); from 190.6 to $271.17 / 10^{5}$ (a rise of $80.5 / 10^{5}$, 95\% CI 38.5-122.7) in cohorts where some or all women were eligible for the prevalent round; and from 287 to $322.2 / 10^{5}$ (a rise of $35.2 / 10^{5}$, 95\% CI -13.1 to 83.5 ) in cohorts who were entering screening during the 'incident round'. In 60-64year olds, cohort incidence changed from 213.1 to 194.6/ $10^{5}$ in the years before screening (a decrease of $18.5 / 10^{5}$, $95 \%$ CI -17.4 to 54.4 ); from 209.53 to $304.8 / 10^{5}$ (a rise of 95.2, 95\% CI 50.8-146) in cohorts where some or all women were eligible for screening in the prevalent round; and from 298.7 to $314.7 / 10^{5}$ in the cohorts beginning screening after the prevalent round was complete (an increase of $16 / 10^{5}, 95 \%$ CI -32.4 to 64.4 ).

Figure 2 shows breast cancer incidence in the same birth cohorts presented in Fig. 1 but for women in the 5-year age-groups below and above the screening ages. There was no appreciable change in incidence in 65-69-year olds from the 1922 to the 1948 birth cohort. Among 45-49-year olds, there was little change in incidence until the 1942 birth cohort and a small but non-significant rise thereafter from 160.6 to 175.3 (a rise of 14.7 cases $/ 10^{5}$ female population, $95 \% \mathrm{CI}-21.1$ to 50.5 ) in the 1948 cohort.

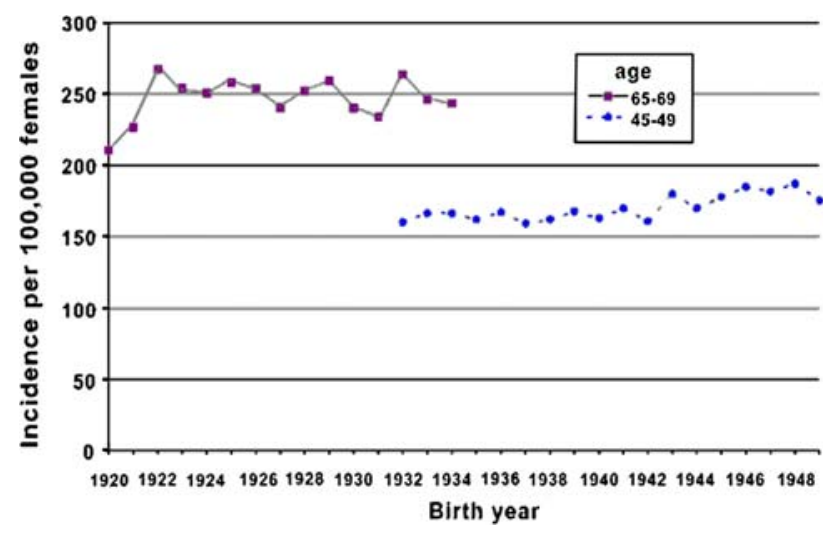

Fig. 2 Breast cancer incidence in women aged 45-49 and 6569 years, by year of birth and age, 1977-2003

\section{Discussion}

Our analysis confirms that significant increases in breast cancer incidence in the United Kingdom have occurred among women who were eligible for screening. The anticipated fall in incidence after the prevalent round of screening had been completed was not observed. Instead, there was a suggestion that continued increases in incidence among 50-64-year old women occurred. Increases in incidence had also been developing before the screening programme began (as demonstrated by the incidence rise with birth cohort in women aged 50-54). True increases in incidence-possibly due to changing reproductive patterns-rather than screening may explain these patterns. Such an explanation is supported by the fact that breast cancer incidence has been shown in many countries worldwide to differ between birth cohorts [3, 6, 13]; women born in different years may have different population risk exposures as a result of trends in fertility while they were in the reproductive years of life and hence have a different risk of breast cancer at all ages. This could impact on population incidence. Several studies have shown links with trends birth cohort incidence of breast cancer and the corresponding population fertility trends related to each birth cohort year [3, 6, 13]. In Scotland, family size has gradually fallen since the 1935 maternal birth cohort year [14] and this may have contributed to a rise in breast cancer incidence.

Hormone replacement therapy increases risk of breast cancer, with a large meta-analysis of trial results concluding that the risk of breast cancer increases by a factor of 1.023 for every year of use and that this increased risk disappeared 5 years after cessation of use. Changes in the population use of HRT could affect population breast cancer risk and hence population breast cancer incidence. Evidence from Australia and the US [15, 16] suggests that breast cancer incidence could reflect population HRT prevalence. The use of hormone replacement therapy in the UK doubled between 1973 and 1976, fell again and began to rise substantially from the late 1980 s onwards; prevalence in England was estimated to have risen from $2.2 \%$ of 45-64-year olds in 1987 to $21.7 \%$ in 1994 [17]. Between the mid-1990 and 2001 prevalence of use did not change [18]. Data obtained by the authors from the Information and Statistics Division suggests a similar pattern occurred in Scotland. This would therefore not support changes in HRT prevalence being responsible for the breast cancer incidence changes seen here.

Birth cohort incidence of breast cancer in Scotland since the advent of the organised mammographic screening programme has not been reported previously. Variation in the activity of the breast screening programme since its inception may have produced apparent birth cohort 
incidence effects that are in fact late temporal observational biases. Entry into the "prevalent" screening programme is transitional in at least three ways. First, the programme was only introduced to women aged 50-64 over a period of 7 years. In the early years, only a minority of the eligible population would have been screened. As coverage of the population gradually increased, an artefactual increase in the incidence of breast cancer would be expected as more asymptomatic cancers were detected than before $[4,5]$. Data on uptake of screening are available from 1990 onwards. These show that about a fifth of all women aged 50-64 participated in prevalent screening each year until it was complete in 1994/1995. The number of incident screens rose through the early 1990s so that by $1992 / 1993$ the number of women screened annually in Scotland reached a plateau of about 100,000 , or about $70 \%$ of those who were invited. Most of the artificial increase in incidence would therefore have ceased after 1994/1995 and some reduction in incidence due to lead-time bias would be expected for a year or more thereafter. Thus the screening programme would not explain the observed sustained increases in breast cancer incidence.

Second, prevalent and follow-up rounds occur simultaneously after several years of a national screening programme. Women in some birth cohorts will have been offered screening during the prevalent round, others will have not been offered screening at all, and some will have been offered screening when the screening programme had long been established. Third, in order to show age and birth cohort specific rates, we have shown 5-year rolling averages. Thus within any given age-group, full eligibility for screening was only achieved after 5 years. In each of the screening groups, the most marked rises in incidence with rising birth cohort year were within the group of women offered screening during the prevalent round. This initial trend might be entirely explained by the increasing national coverage of the Scottish population by screening. Incidence increased with each birth cohort year. However, this does not explain the continued increase in incidence seen with successive birth cohorts in the 50-54 and 55-59 age-groups after the prevalent round had been completed. There were no major technical changes in the screening programme [19] after this time to account for this continued rise. Although confidence intervals for these rises are wide it still appears that this is a true birth cohort effect. In women aged 60-64 during established screening the relationship of incidence to birth cohort was less clear. In women aged 4549 a non-significant rise in breast cancer incidence was developing from the 1942 cohort onward; in women aged 65-69 there was little change in breast cancer incidence across the different birth cohorts. It may be that in women aged 65-69, the general effect of ageing on cancer incidence is of greater importance than reproductive risk factors.

There are several limitations to this population-based study. One is the potential for misclassification of screening experience. For example, not all women of eligible age were offered or took-up breast screening between 1987 and 1994. However, uptake of breast screening invitations in the NHS breast screening programme in the UK has changed little since the start of the programme [19] and thus variations in screening uptake should not be a significant source of error. The study method attempted to minimise the potential for misclassification by calculating incidence rates for individual birth cohort years instead of ranges, and dividing women into groups based on a calculation of their likely exposure to screening. Many women being screened during the introduction of the prevalent round may in fact have also had a subsequent screen but are still counted amongst 'women being screened during the prevalent round' as it is the overall effect of the prevalent round on the group that is of interest.

In conclusion, while some of the increases in breast cancer incidence in Scotland in women aged 45-64 can be explained by the prevalent round of screening, continued rises in incidence with later birth cohorts are not readily explained by the screening programme. The reasons for the true increase in birth cohort incidence are uncertain. Possible contributing factors are changes in reproductive and hormonal factors such as changing fertility patterns $[3,6$, $13,14]$ or changes in HRT prevalence.

Acknowledgments We would like to acknowledge the late Professor David Hole who proposed the hypothesis and designed the study.

Funding This study was performed as part of doctorate studies and was not funded.

\section{References}

1. Breast cancer incidence data (2005) Scottish Executive Information \& Statistics Division, Scotland

2. Brown SBF, Hole DJ, Cooke TG (2006) Breast cancer incidence trends in deprived and affluent Scottish women. Breast Cancer Res Treat 103(2):233-238

3. Swerdlow AJ, dos Santos Silva I, Reid A, Qiao Z, Brewster DH, Arrundale J (1998) Trends in cancer incidence and mortality in Scotland: description and possible explanations. $\mathrm{Br} \mathrm{J}$ Cancer 77(Suppl 3):1-54

4. Moller B, Weedon-Fekjaer H, Hakulinen T, Tryggvadottir L, Storm HH, Talback $M$ et al (2005) The influence of mammographic screening on national trends in breast cancer incidence. Eur J Cancer Prev 14:117-128. doi:10.1097/00008469-2005 04000-00007

5. Schouten LJ, de Rijke JM, Huveneers JA, Verbeek AL (2002) Rising incidence of breast cancer after completion of the first 
prevalent round of the breast cancer screening programme. J Med Screen 9:120-124. doi:10.1136/jms.9.3.120

6. Chia KS, Reilly M, Tan CS, Lee J, Pawitan Y, Adami HO et al (2005) Profound changes in breast cancer incidence may reflect changes into a Westernized lifestyle: a comparative populationbased study in Singapore and Sweden. Int J Cancer 113:302-306. doi:10.1002/ijc. 20561

7. Colditz GA (2005) Epidemiology and prevention of breast cancer. Cancer Epidemiol Biomarkers Prev 14:768-772. doi: 10.1158/1055-9965.EPI-04-0157

8. Rosner B, Colditz GA, Willett WC (1994) Reproductive risk factors in a prospective study of breast cancer: the Nurses' Health Study. Am J Epidemiol 139:819-835

9. Pathak DR, Whittemore AS (1992) Combined effects of body size, parity, and menstrual events on breast cancer incidence in seven countries. Am J Epidemiol 135:153-168

10. Pike MC, Krailo MD, Henderson BE, Casagrande JT, Hoel DG (1983) 'Hormonal' risk factors, 'breast tissue age' and the ageincidence of breast cancer. Nature 303:767-770. doi: $10.1038 / 303767 \mathrm{a} 0$

11. Singletary KW, Gapstur SM (2001) Alcohol and breast cancer: review of epidemiologic and experimental evidence and potential mechanisms. JAMA 286(17):2143-2151. doi:10.1001/jama.286. 17.2143
12. Newcombe RG, Altman DG (2000) Proportions and their differences. In: Altman D, Machin D, Bryant T, Gardner S (eds) Statistics with confidence, Ch 6, 2nd edn. BMJ Books, London

13. dos Santos Silva I, Swerdlow AJ (1995) Recent trends in incidence of and mortality from breast, ovarian and endometrial cancers in England and Wales and their relation to changing fertility and oral contraceptive use. Br J Cancer 72:485-492

14. Cumulative fertility data at age 44 by maternal birth cohort (2006) General Register Office-Scotland

15. Ravdin PM, Cronin KA, Howlader N, Berg CD, Chlebowski RT, Feuer EJ et al (2007) The decrease in breast-cancer incidence in 2003 in the United States. N Engl J Med 356(16):1670-1674. doi: 10.1056/NEJMsr070105

16. Coombs NJ, Taylor R, Wilcken N, Boyages J (2005) HRT and breast cancer: impact on population risk and incidence. Eur $\mathrm{J}$ Cancer 41:1775-1781. doi:10.1016/j.ejca.2005.03.030

17. Townsend $\mathbf{J}$ (1998) Hormone replacement therapy: assessment of present use, costs, and trends. Br J Gen Pract 48:955-958

18. Townsend J, Nanchahal K (2005) Hormone replacement therapy: limited response in the UK to the new evidence. $\mathrm{Br} \mathrm{J}$ Gen Pract 55:555

19. Blanks RG, Moss SM, Patnick J (2000) Results from the UK NHS breast screening programme 1994-1999. J Med Screen 7:195-198. doi:10.1136/jms.7.4.195 